\title{
Thyroid Volume Predicts Body Mass Index 2 and 6 Years Later
}

\author{
Daniel Litu Chen ${ }^{\mathrm{a}, \mathrm{b}, \mathrm{g}}$, Katherine Tonks, ${ }^{\mathrm{a}, \mathrm{b}}$, Jerry R. Greenfield ${ }^{\mathrm{a}, \mathrm{b}}$, Charles El-Nouty, \\ Serge Hercberg ${ }^{\mathrm{c}, \mathrm{d}}$, Sebastien Czernichow ${ }^{\mathrm{e}, \mathrm{f}}$
}

\begin{abstract}
Background: Thyroid volume correlates positively with body mass index (BMI). This correlation holds true for both iodine-sufficient and mild/moderate iodine-deficient areas. We examined the association between thyroid volume and BMI and change in BMI over 4 years in middle-age adults recruited from the general population.
\end{abstract}

Methods: A total of 2,495 subjects, for whom thyroid volume, FT4 and TSH were available (women aged 35 - 60 years and men aged 45 - 60 years), were derived from the Supplementation en Vitamines et Mineraux Antioxydants (SU.VI. MAX) cohort study conducted in France since baseline (1994). Weight and height were measured 2 and 6 years after inclusion. Linear univariate and multiple regression analyses were performed to evaluate correlations between thyroid volume and BMI at 2 and 6 years and BMI change from year 2 to 6 .

Results: Baseline thyroid volume was positively correlated with BMI at 2 years (men: $\beta=0.09, \mathrm{P}<0.01$; women: $\beta=0.09, \mathrm{P}<0.01$ ) and 6 years after inclusion (men: $\beta=0.10, P<0.01$; women: $\beta=$ $0.09, \mathrm{P}<0.01$ ). The correlation between thyroid volume and BMI at 2 and 6 years remained significant after adjusting for free T4, $\mathrm{TSH}$, gender, age, smoking, alcohol consumption and TSH-thyroid volume interaction factor $(\beta=0.11, \mathrm{P}<0.01)$. Baseline thyroid volume was not correlated with BMI change from year 2 to 6 in linear regression analysis.

\footnotetext{
Manuscript accepted for publication June 20, 2012

${ }^{a}$ Department of Endocrinology, St Vincent's Hospital, Sydney, Australia

${ }^{\mathrm{b}}$ Garvan Institute of Medical Research and University of New South

Wales, Sydney, Australia

${ }^{c}$ UMR (INSERM U557, INRA, CNAM, UP13), Universite Paris 13,

Bobigny, France

${ }^{\mathrm{d}}$ Departement de Sante Publique, Hopital Avicenne, Bobigny, France

${ }^{\mathrm{e}}$ Nutrition Departement, Hopital Ambroise Pare, Boulogne-Billancourt,

France

${ }^{\mathrm{f}}$ Universite Versailles St-Quentin, Boulogne-Billancourt, France

${ }^{g}$ Corresponding author: Daniel Li Tu Chen.

Email: d.chen@garvan.org.au
}

doi:10.4021/jem 99 w
Conclusions: In French adults, thyroid volume predicted BMI at 2 and 6 years. Further studies are needed to explore the association between thyroid volume and BMI.

Keywords: Body mass index; Thyroid volume; Weight change; Population study

\section{Introduction}

Observational epidemiological studies have reported a positive correlation between thyroid volume and body weight [1], body mass index (BMI) [2, 3], body surface area [2] and lean body mass [4]. These correlations are observed in both iodine-sufficient and mild/moderate iodine-deficient areas $[1,3,5]$. However, studies are cross-sectional and cannot define causality. To date, there have been no studies that have examined the association between thyroid volume and BMI a number of years later.

We examined the correlation between thyroid volume and BMI 2 and 6 years later in a group of middle-age adults participating to the Supplementation en Vitamines et Mineraux Antioxydants (SU.VI.MAX) French cohort.

\section{Materials and Methods}

\section{Subjects}

We undertook an analysis of data collected in the SU.VI. MAX study. This study was conducted in France. Subjects were participants of the SU.VI.MAX study, initially designed as a randomized, double-blind, placebo-controlled, primary prevention trial to test the potential efficacy of daily supplementation with antioxidant vitamins and minerals at nutritional doses (ascorbic acid, vitamin E, beta-carotene, selenium and zinc) on the risk of cancer, ischemic heart diseases and total mortality. The design and rationale of the SU.VI.MAX study (Supplementation en Vitamines et Mineraux Antioxydants) have been extensively detailed previ- 
Table 1. Characteristics of SU.VI.MAX Cohort

\begin{tabular}{lcccc}
\hline & \multicolumn{2}{c}{ Men n $\mathbf{1 , 0 0 1}$} & \multicolumn{2}{c}{ Women n = 1,494 } \\
\cline { 2 - 4 } Variables & Mean \pm SD & $\mathbf{n}$ & Mean \pm SD & $\mathbf{n}$ \\
\hline Thyroid volume $(\mathrm{mL})$ & $14.3 \pm 5.5$ & 1,001 & $9.6 \pm 3.7$ & 1,494 \\
TSH $(\mathrm{mU} / \mathrm{L})$ & $1.7 \pm 1.0$ & 1,001 & $2.2 \pm 1.5$ & 1,494 \\
Free T4 $(\mathrm{pmol} / \mathrm{L})$ & $13.7 \pm 1.9$ & 1,001 & $14.0 \pm 1.9$ & 1,494 \\
Weight 2 years after inclusion $(\mathrm{kg})$ & $76.3 \pm 10.1$ & 1,001 & $59.8 \pm 9.4$ & 1,494 \\
Weight 6 years after inclusion $(\mathrm{kg})$ & $78.3 \pm 10.6$ & 1,001 & $61.8 \pm 10.2$ & 1,494 \\
Weight change $(\mathrm{kg})$ & $2.0 \pm 5.1$ & 1,001 & $2.1 \pm 5.6$ & 1,494 \\
BMI 2 years after inclusion $\left(\mathrm{kg} / \mathrm{m}^{2}\right)$ & $25.3 \pm 2.9$ & 1,001 & $22.8 \pm 3.3$ & 1,494 \\
BMI 6 years after inclusion $\left(\mathrm{kg} / \mathrm{m}^{2}\right)$ & $26.0 \pm 3.1$ & 1,001 & $23.6 \pm 3.6$ & 1,494 \\
BMI change $\left(\mathrm{kg} / \mathrm{m}^{2}\right)$ & $0.7 \pm 1.7$ & 1,001 & $0.8 \pm 2.2$ & 1,494 \\
Alcohol Consumption $(\%)$ & 76.4 & 994 & 51.7 & 1,490 \\
Tobacco Consumption $(\%)$ & 52.0 & 965 & 28.6 & 1,448 \\
\hline
\end{tabular}

ously [6]. Eligible subjects, 7,713 women aged 35 - 60 years and 5,028 men aged 45 - 60 years at baseline, were included in 1994 - 1995 and followed up for 7.5 y [7]. During the follow-up, all participants underwent an annual visit, with alternating blood sampling (at baseline) or clinical examination (1995 - 1996), every other year. They also provided information regarding health, diet, drugs and various lifestyle indicators. On a subsample of 3,523 subjects, thyroid volume was assessed at baseline, through the use of a mobile unit ('ThyroMobil van'), equipped with an ultrasound machine. We analysed the relationship between thyroid volume and weight and BMI at 2 and 6 years. Twenty-one percent of male subjects and $13 \%$ of female subjects did not have weight measurement 2 and 6 years after inclusion. Thus, 1,001 men and 1,494 women completed weight and height measurement 2 and 6 years after inclusion.

Several exclusion criteria were applied: goitre, signs of previous or current thyroid disease, treatment with thyroid hormones, antithyroid drugs and lithium treatment. Twenty subjects with urinary iodine concentration $\geq 60 \mu \mathrm{g} / 100 \mathrm{~mL}$ were eliminated, as was one subject with thiocyanate overload (urinary thiocyanate concentration $\geq 50 \mathrm{mg} / \mathrm{L}$ ). The final study group consisted of 1,274 men and 1,713 women.

The SU.VI.MAX study was approved by the Ethical Committee for Studies with Human Subjects of the ParisCochin Hospital (CCPPRB No. 706) and the "Commission Nationale Informatique et Liberté" (CNIL No. 334641), which ensures that medical information be kept confidential and anonymous.

\section{Thyroid volume}

Thyroid volume was estimated using a high frequency 7.5 $\mathrm{MHz}$ linear array transducer (Sonoline SI-400, Siemens, Erlangen, Germany). The examination was performed with the patient in a supine position with the neck hyperextended. The isthmus was not taken into account in volume calculation. Nodules and/or cystic areas were included in volume determination. All ultrasonographic examinations were performed and interpreted by the same radiologist.

\section{Anthropometry}

Weight was measured 2 and 6 years after inclusion with an electronic scale (Seca, Germany) with subjects in indoor clothing and no shoes. Height was measured with a wallmounted stadiometer with no shoes to the nearest $0.5 \mathrm{~cm}$. BMI was calculated as weight divided by height squared $(\mathrm{kg} /$ $\left.\mathrm{m}^{2}\right)$.

\section{Statistical analysis}

Men and women were evaluated separately. The relationship between baseline thyroid volume and BMI at 2 and 6 years was estimated by linear univariate analysis. Multiple linear regression was used to adjust for potential confounders in- 
Table 2. Linear Regression Analysis of BMI 2 and 6 Years After Inclusion With Baseline Characteristics $(n=2,413)$

\begin{tabular}{|c|c|c|c|c|}
\hline \multirow{2}{*}{2 years } & \multicolumn{2}{|c|}{ Men } & \multicolumn{2}{|c|}{ Women } \\
\hline & Beta & P value & Beta & P value \\
\hline Age (yr) & 0.05 & 0.02 & 0.12 & $<0.001$ \\
\hline $\mathrm{TSH}(\mathrm{mU} / \mathrm{L})$ & 0.05 & 0.55 & 0.09 & 0.12 \\
\hline Free T4 (pmol/L) & -0.08 & 0.09 & 0.01 & 0.77 \\
\hline Thyroid volume (mL) & 0.09 & $<0.001$ & 0.09 & $<0.001$ \\
\hline Alcohol consumption (\%) & 0.42 & 0.06 & 0.10 & 0.54 \\
\hline Tobacco consumption $(\%)$ & 0.38 & 0.04 & 0.30 & 0.12 \\
\hline \multicolumn{5}{|l|}{6 years } \\
\hline Age (yr) & 0.04 & 0.05 & 0.10 & $<0.001$ \\
\hline $\mathrm{TSH}(\mathrm{mU} / \mathrm{L})$ & 0.001 & 0.99 & -0.02 & 0.73 \\
\hline Free T4 (pmol/L) & -0.07 & 0.17 & 0.004 & 0.94 \\
\hline Thyroid volume (mL) & 0.10 & $<0.001$ & 0.09 & $<0.001$ \\
\hline Alcohol consumption (\%) & 0.08 & 0.74 & 0.21 & 0.26 \\
\hline Tobacco consumption (\%) & 0.44 & 0.03 & 0.36 & 0.09 \\
\hline
\end{tabular}

cluding age, TSH, free T4, alcohol and tobacco consumption to consolidate the relationship between baseline thyroid volume and BMI at 2 and 6 years. Data were analysed using 'version 9.1' SAS statistical software (SAS Institute, Cary, USA).

\section{Results}

Baseline thyroid volume, TSH, free T4 (fT4) and BMI 2 and 6 years after inclusion are shown in Table 1. Mean BMI 2 years after inclusion was $25.3 \pm 2.9 \mathrm{~kg} / \mathrm{m}^{2}$ in men and $22.8 \pm$ $3.3 \mathrm{~kg} / \mathrm{m}^{2}$ in women; mean BMI 6 years after inclusion was $26.0 \pm 3.1 \mathrm{~kg} / \mathrm{m}^{2}$ in men and $23.6 \pm 3.6 \mathrm{~kg} / \mathrm{m}^{2}$ in women. The mean weight change between the 2 nd and 6 th years was $2 \pm$ $5.4 \mathrm{~kg}$. Mean thyroid volume at inclusion was $11.5 \pm 5 \mathrm{~mL}$. The median thyroid volume was $13.2 \mathrm{~mL}$ in men and $9.1 \mathrm{~mL}$ in women.

Baseline thyroid volume was positively correlated with BMI 2 years (men: $\beta=0.09, \mathrm{P}<0.01$; women: $\beta=0.09, \mathrm{P}<$ 0.01 ) and 6 years (men: $\beta=0.01, P<0.01$; women: $\beta=0.09$,
$\mathrm{P}<0.01$ ) after inclusion (Table 2). In the total cohort, correlations between baseline thyroid volume and BMI at 2 and 6 years remained significant after adjusting for gender, age, TSH, fT4, smoking and alcohol consumption (BMI 2 years: $\beta=0.11, \mathrm{P}<0.01$; BMI 6 years: $\beta=0.11, \mathrm{P}<0.01$ ).

Baseline TSH was negatively correlated with weight change $(\beta=-0.25, \mathrm{P}<0.01)$, but not thyroid volume $(\mathrm{P}=$ $0.77)$ or free T4 $(\mathrm{P}=0.96)$. The correlation between TSH and weight change was eliminated after adjusting for other variables including gender, free T4, alcohol/tobacco consumption (men: $\mathrm{P}=0.84$, women: $\mathrm{P}=0.88$ ).

\section{Discussion}

Our study demonstrates that thyroid volume is positively correlated with BMI at 2 and 6 years, even after adjusting for other variables, such as fT4, TSH, gender and age. This is the first study to examine the correlation between thyroid volume and BMI 2 and 6 years later. Previous studies have 


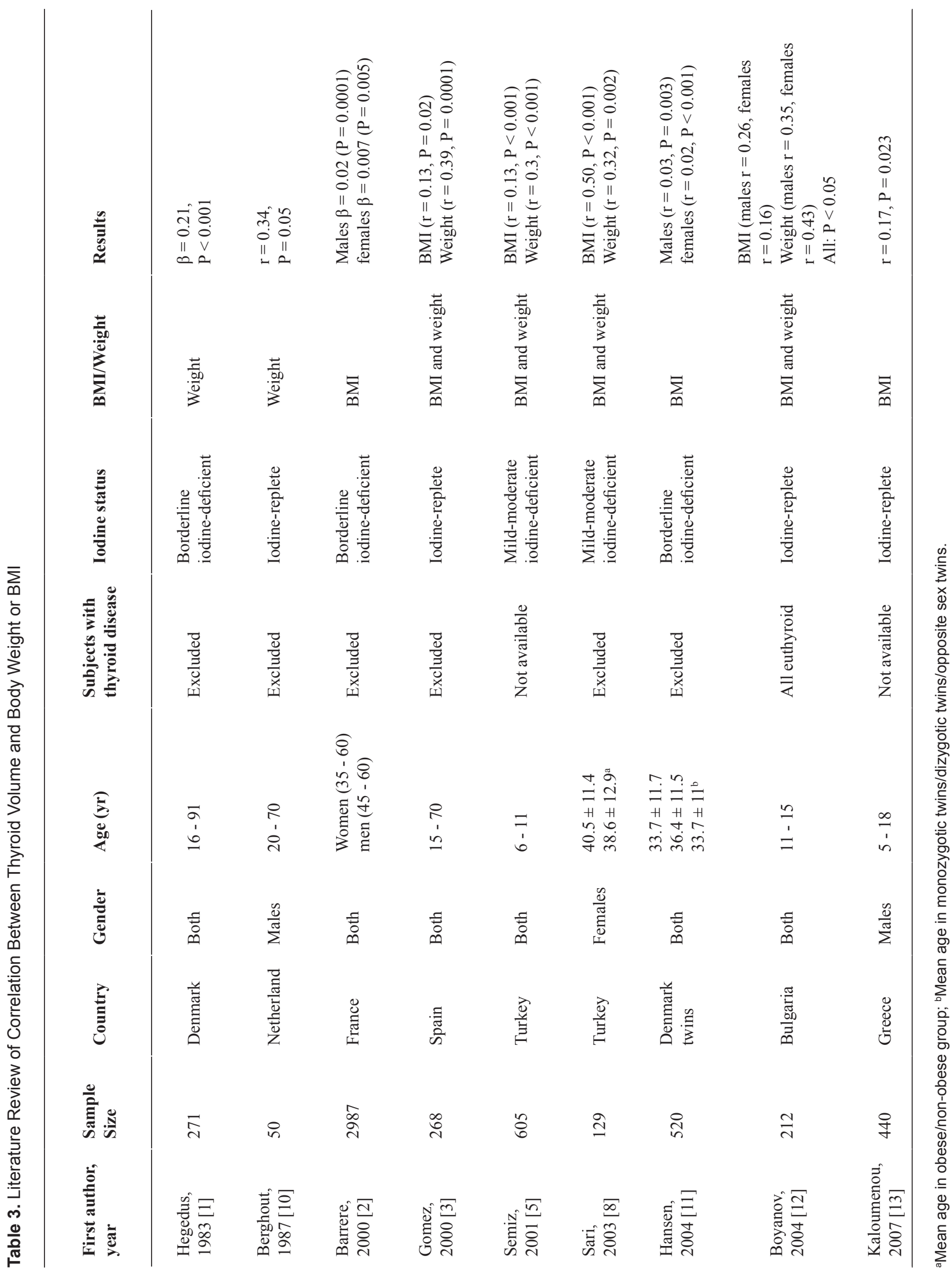


evaluated the association between thyroid volume and BMI or body weight at one point in time (Table 3). These studies have all demonstrated a positive correlation between thyroid volume and BMI/body weight.

Our study did not show any significant correlation between baseline thyroid volume and weight change between 2 and 6 years. Although TSH correlated negatively with weight change, this correlation became insignificant after adjusting for other confounders. The lack of marked weight change over 4 years may undermine any possible significant correlation between thyroid volume and weight change. Other explanations could be due to the low heterogeneity in the study population and a short follow-up period between measurements. Two studies have examined the effect of weight loss on thyroid volume changes. Sari [8] examined intentional weight loss over 6 months using sibutramine 15 $\mathrm{mg} /$ day and/or orlistat $360 \mathrm{mg} /$ day and its effect on thyroid volume. Wesche [9] evaluated correlation between 6 months of intensive rowing training and thyroid volume in lean subjects. Both studies achieved significant weight loss $(>10 \%$ of body weight and mean weight loss of $2.5 \mathrm{~kg}$ respectively) and demonstrated a positive correlation between weight loss and reduction in thyroid volume.

Our study had some limitations. Firstly, thyroid volume was only measured at baseline. Secondly, as this was an observational study, we cannot draw causal inferences regarding to the association between thyroid volume and BMI. Therefore, there may be potential confounders that contribute to BMI other than baseline thyroid volume.

In summary, our study shows that baseline thyroid volume predicts BMI 2 and 6 years later. Further studies are needed to explore the association between thyroid volume, and BMI.

\section{Acknowledgement}

We thank Stephen Besseau, UMR (INSERM U557, INRA, CNAM, UP13), Universite Paris 13, Bobigny, France for his support in performing statistical analysis.

\section{Conflict of Interest}

All authors declare no conflict of interest.

\section{References}

1. Hegedus L, Perrild H, Poulsen LR, Andersen JR, Holm B, Schnohr P, Jensen G, et al. The determination of thyroid volume by ultrasound and its relationship to body weight, age, and sex in normal subjects. J Clin Endocrinol Metab. 1983;56(2):260-263.
2. Barrere X, Valeix P, Preziosi P, Bensimon M, Pelletier B, Galan P, Hercberg S. Determinants of thyroid volume in healthy French adults participating in the SU.VI.MAX cohort. Clin Endocrinol (Oxf). 2000;52(3):273-278.

3. Gomez JM, Maravall FJ, Gomez N, Guma A, Soler J. Determinants of thyroid volume as measured by ultrasonography in healthy adults randomly selected. Clin Endocrinol (Oxf). 2000;53(5):629-634.

4. Wesche MF, Wiersinga WM, Smits NJ. Lean body mass as a determinant of thyroid size. Clin Endocrinol (Oxf). 1998;48(6):701-706.

5. Semiz S, Senol U, Bircan, Gumuslu S, Bilmen S, Bircan I. Correlation between age, body size and thyroid volume in an endemic area. J Endocrinol Invest. 2001;24(8):559-563.

6. Hercberg S, Galan P, Preziosi P, Roussel AM, Arnaud J, Richard MJ, Malvy D, et al. Background and rationale behind the SU.VI.MAX Study, a prevention trial using nutritional doses of a combination of antioxidant vitamins and minerals to reduce cardiovascular diseases and cancers. SUpplementation en VItamines et Mineraux AntioXydants Study. Int J Vitam Nutr Res. 1998;68(1):3-20.

7. Hercberg S, Galan P, Preziosi P, Bertrais S, Mennen L, Malvy D, Roussel AM, et al. The SU.VI.MAX Study: a randomized, placebo-controlled trial of the health effects of antioxidant vitamins and minerals. Arch Intern Med. 2004;164(21):2335-2342.

8. Sari R, Balci MK, Altunbas H, Karayalcin U. The effect of body weight and weight loss on thyroid volume and function in obese women. Clin Endocrinol (Oxf). 2003;59(2):258-262.

9. Wesche MF, Wiersinga WM. Relation between lean body mass and thyroid volume in competition rowers before and during intensive physical training. Horm Metab Res. 2001;33(7):423-427.

10. Berghout A, Wiersinga WM, Smits NJ, Touber JL. Determinants of thyroid volume as measured by ultrasonography in healthy adults in a non-iodine deficient area. Clin Endocrinol (Oxf). 1987;26(3):273-280.

11. Hansen PS, Brix TH, Bennedbaek FN, Bonnema SJ, Kyvik KO, Hegedus L. Genetic and environmental causes of individual differences in thyroid size: a study of healthy Danish twins. J Clin Endocrinol Metab. 2004;89(5):2071-2077.

12. Boyanov MA, Temelkova NL, Popivanov PP. Determinants of thyroid volume in schoolchildren: fat-free mass versus body fat mass--a cross-sectional study. Endocr Pract. 2004;10(5):409-416.

13. Kaloumenou I, Alevizaki M, Ladopoulos C, Antoniou A, Duntas LH, Mastorakos G, Chiotis D, et al. Thyroid volume and echostructure in schoolchildren living in an iodine-replete area: relation to age, pubertal stage, and body mass index. Thyroid. 2007;17(9):875-881. 